\title{
Figuración vs. Abstracción. El caso del concurso escultórico de La Marinera. Lima, 1958
}

Manuel Munive

En el ámbito cultural de la Lima de los años cincuenta, del siglo XX, se mantenía latente la brecha que abrió entre los "diletantes" el surgimiento de la abstracción plástica o "no figurativa"'. Esta tendencia, predominantemente pictórica en nuestro medio, había creado un verdadero impasse entre aquel público asiduo a exposiciones, conferencias y actividades culturales diversas, quienes hasta hacía poco disfrutaban de la pose del amateur o del conocedor de las "Bellas Artes". Posturas en realidad decimonónicas, como lo era también, en sus fundamentos, la formación impartida en nuestra Escuela de Bellas Artes -hasta la aparición de la figura de Sabogal y el Indigenismo o hasta la mirada hacia las formas del Perú Antiguo en conjunción con las hispanas en el caso de la obra de Manuel Piqueras Cotoli-. Completamente alejado de la realidad cultural que primaba en otras capitales del mundo como consecuencia de la posguerra, el ambiente cultural limeño estaba poblado por adeptos cuyo provincianismo medular se hacía patente en la solemnidad "parisina", en todo caso, "europeizante" con que se involucraban con el hecho artístico, para quienes lo "no figurativo" representó un escollo para su comprensión y sus hábitos.

Contemplando esto podemos sopesar la importancia de la labor de algunos críticos que se vieron en la obligación de despejar el camino de este tipo de lastres que tendía a convertir lo cultural en un "entremés" social estéril, colmado de brindis, retórica hueca y amaneramiento. Entre estos críticos destacamos la actividad de Sebastián Salazar Bondy. En este breve trabajo podremos apreciar su despliegue como tal cuando, como miembro del jurado de un concurso escultórico, en cabal asunción de su rol esclarecedor, sin los temores de afectar susceptibilidades, sea de quien fueren, se vio obligado a sustentar las razones de su elección estética cuando el organizador del concurso, y por ende quien pagaba el premio con dinero de su bolsillo, puso en duda el veredicto de un jurado cuyos miembros, uno a uno, fueron retractándose hasta dejarlo prácticamente solo en la discusión.

\footnotetext{
" Los conceptos de "abstracción" y "no figuración" funcionan como sinónimos únicamente en el campo de la historia de las artes plásticas, esfera en la que ya resulta imposible corregir esta imprecisión. Abstraer significa esencialmente "sintetizar"e incluso "estilizar", algo que han hecho los pintores rupestres de Tassili Najer así como quienes diseñaron las figuras que reconocemos, no $\sin$ un poco de esfuerzo, en los textiles Wari. La "no figuración" es un concepto acuñado para abordar las manifestaciones artísticas del siglo XX, particularmente desde la aparición de la "acuarela abstracta" de Kandinsky, en 1910.
} 
Pretendemos, en suma, mediante este específico caso ocurrido a fines de la década de los años cincuenta, echar luz sobre una época relativamente cercana en la que, sin embargo, se adoptaron posturas visiblemente anacrónicas. También tratar de explicar, parcialmente, el origen de las defecciones que incluso hoy persisten, tales como la ineficacia para crear un Museo de Arte Contemporáneo, institución cuya realización se ha tornado en casi una utopía entre nosotros pues de nada han servido las acciones que durante cuatro décadas sus gestores han emprendido, gestiones en las que la retórica y las buenas intenciones han sido pródigas. Podremos ver también, de modo ejemplar, la ambigua posición de quienes entonces se denominaban "entendidos" en materia de artes plásticas y que, paradójicamente, parecen los menos indicados para concretar proyectos culturales de trascendencia.

\section{Cronología del concurso}

La edición de la mañana del diario El Comercio del jueves 28 de mayo de 1958 publicó en su página 17: "Concurso escultórico convocan sobre el tema de la marinera". Quien convocaba este concurso era el doctor César Revoredo, abogado ilustre de Lima y acendrado propulsor de actividades culturales, todas ellas orientadas a cultivar las "tradiciones" del Perú, con particular énfasis en aquellas supuestamente fraguadas durante el virreinato y particularmente en Lima. Podemos decir que en el doctor Revoredo encontrábanse entremezcladas las características del peruanista, el hispanista, el tradicionalista, el criollista y el limeñista que había encontrado en las Tradiciones peruanas de Ricardo Palma un evangelio. El propósito de este concurso era el de proveer de un monumento o emblema escultórico a la célebre danza popular de pareja denominada La Marinera, que antes de la Guerra del Pacífico tenía entre una de sus denominaciones la de Chilena, cambio sugerido por Abelardo Gamarra El Tunante, autor de la primera marinera titulada Antofagasta.

El viernes 8 de agosto se publicó lo siguiente: "Premio concurso sobre Marinera dan el lunes". En esta nota se informa que fueron catorce los escultores peruanos participantes en este concurso "convocado a propósito de la Semana de la Tradición (...) La obra que será galardonada, y que debe estar inspirada en formas plásticas que evoquen las esencias de nuestro baile tradicional, servirá más tarde como modelo para erigir un monumento en un paseo público". El jurado estaría conformado por Marisa Pinilla de Mujica, Julia Codesido, Ernesto Aramburú, Sebastián Salazar Bondy, Joaquín Roca Rey y Luis Valdettaro. La primera, Presidenta de la Comisión Organizadora de la Semana de la Tradición, no integraría el jurado, el cual quedó conformado finalmente por Codesido y Aramburú, pintores, y Roca Rey y Valdettaro, escultores. Salazar Bondy sería el único crítico en el grupo y, como se notará más adelante, no fue elegido precisamente por amistad, como pudo suceder con los demás miembros, sino por su relación con el Instituto de Arte Contemporáneo, sede de las deliberaciones y en una de cuyas salas se exhibirían las maquetas finalistas y la premiada.

Casi tres meses después de convocado el concurso, el sábado 16 de agosto se divulgó el nombre del ganador: "Escultor Alberto Guzmán ganó concurso La Marinera". (Fig.1) Se informa además que dicho escultor "es discípulo de Joaquín Roca Rey" en la Escuela Nacional de Bellas Artes. Esta relación posiblemente llevó a Roca Rey a permanecer en silencio durante la polémica que surgiría inmediatamente después de la elección. La maqueta premiada representa una estilizada mujer erguida que con la mano izquierda recogé. ${ }^{-1}$ l vuelo de 
su falda y que lleva la derecha a la altura del pecho, seguramente, con un pañuelo -hasta este punto son precarias las reproducciones con las que contamos. El pie derecho apunta hacia delante y el izquierdo detrás, en forma de una " $T$ ". Es decir, nada revolucionario formalmente, aunque sí para los "tradicionalistas" que debieron sentirse defraudados por la falta de "rimbombancia" a la que estaban acostumbrados pues la figurina de Guzmán era más bien adusta y en su óptima interpretación alegórica, había prescindido de aquello tan "criollo" conocido como "lisura".

Después de anunciado el veredicto el doctor Revoredo debió exteriorizar tan efusivamente su disconformidad que instó a Salazar Bondy a publicar en La Prensa, diario del que era columnista, una carta aclaratoria ${ }^{2}$ en la que sustentó las razones de su elección y en la que aprovechó para poner "en su sitio" al supuesto "mecenas". Posiblemente esta afrenta pública indignó más que las ideas esgrimidas para avalar el fallo del concurso pues el referido doctor era una personalidad con mucha influencia.

A continuación algunos extractos de la carta de Salazar Bondy:

"El señor Revoredo declara ahora, con una singular falta de delicadeza, que entregará el galardón a su legítimo ganador no obstante considerar que el fallo del tribunal no fue acertado. De ese modo, menoscaba los méritos del artista triunfador y pone en tela de juicio la desinteresada tarea de los cinco miembros del jurado (...) En la deliberación del jurado, la mayoría estuvo de acuerdo en que de lo que se trataba en primer lugar era de escoger una escultura, una obra de arte, y no -como parece que pretendía el donador de los 10000 soles- señalar cuál de las piezas era la exacta reproducción de la danza popular. (...) somos los miembros del jurado los que nos podemos mostrar descontentos con la tardía reacción del 'mecenas', quien nos encomendó la dación del premio y la previa elaboración del reglamento al cual debían ceñirse los concurrentes. (...) Las obras presentadas al certamen fueron, en general, mediocres. Sólo la del que luego resultó ganador reunía, en opinión personal del que esto escribe, los valores deseables en una obra escultórica: modelado, gracia, originalidad, sentido del volumen, movimiento, etc. (...) Claro que el señor Revoredo hubiera querido que en la obra aparecieran sombreros de paja, ponchos de hilo, zapatos de tacón y otros de los elementos folklóricos convencionales que aparecen generalmente en las estereotipadas versiones del folklore costeño, los que además de falsos son, sin duda alguna, de un muy dudoso gusto. Guzmán García, que es escultor y no fotógrafo, que es artista y no cronista, que crea y no documenta, realizó una pieza de finas formas y sencillo contenido. No es la 'Marinera', aunque el nacionalismo de algunos se sienta tocado, un tema para Rodin o Henry Moore. (...) Sería recomendable que aquel señor se ilustrara (...) sobre la esencia y sentido de la escultura, ya que se siente tan bien dispuesto a convocar

2 SALAZAR BONDY, Sebastián. "Marinera, escultura y premio". En: La Prensa. Lima, 21 de agosto de 1958. P: 12. 
concursos de ese género. (...) El refrán proclama, en fin, algo que el señor Revoredo parece haber olvidado: 'Zapatero, a tus zapatos'".

Dos días después se iniciaría una intensa polémica a la que se sumaban quienes estaban de lado del "mecenas". Precisamente fue un miembro del jurado, el escultor Luis Valdettaro, quien empezaría con las "confesiones". Esto se pudo leer el sábado 23 de agosto en El Comercio: "Concurso La Marinera / Luis Valdettaro discrepa del fallo". En esta carta el escultor Valdettaro manifiesta : "Tratándose de una obra decorativa con sentido de interpretación rítmica, como es el baile en sentido general, debe procurarse de todos modos plasmar principalmente su belleza de conjunto. Refiriéndonos concretamente a La Marinera, baile que desde luego puede ser motivo de la más elevada concepción artística dada la armonía de sus movimientos, tiene que interpretarse en lo que él realmente constituye permanencia y móvil, o esa la figura de sus dos bailarines que siempre están cara a cara, frente y cerca uno de otro. La figura femenina plasmada individualmente no puede interpretar acertadamente el tema artístico de baile cuando éste para ejecutarlo requiere indispensablemente del otro bailarin (...) Dentro de estas apreciaciones mi opinión tuvo que inclinarse al grupo escultórico cuyo seudónimo era "Aries", y que en mi concepto, repito, interpretaba el tema del baile La Marinera, con más fidelidad artística".

A partir de este momento el concepto de "fidelidad" a la "tradición" en la interpretación del motivo serviría de argumento a quienes estaban en contra del premio otorgado a la estilización escultórica de Alberto Guzmán.

El domingo 24 de agosto El Comercio publicó "Edmundo Pizarro aclara nota sobre premio a la marinera". Pizarro, en calidad de "amigo y colaborador personal del Dr. César Revoredo", respondió la cáustica carta de Salazar Bondy que osó "zaherir a quien con la más sana intención y espíritu nacionalista promovió un concurso para la exaltación de uno de los más interesantes aspectos de nuestro folklore". Rectifica a Salazar Bondy citando a Revoredo quien, contra lo que Salazar Bondy manifestó, no pretendia "hacer ningún enjuiciamiento crítico acerca de las cualidades artisticas de este trabajo, pero discrepa mi opinión de la del Jurado, porque estimo que el boceto ganador no ha interpretado el tema a propósito del Concurso...". Pizarro le recuerda al crítico que "no hubo la mayoría que Ud. Afirma. Es decir, en principio si la hubo, cuando el señor Joaquín Roca Rey, Srta. Julia Codesido y Ud. acordaron que se escogería una obra de arte. Mas cuando el Dr. Revoredo -que estuvo presente en esta primera reunión-manifestó su punto de vista, la Srta. Codesido retiró su voto y el Sr. Valdettaro se abstuvo de votar". Hasta ese punto resultó disuasiva la opinión del patrocinador. Esta situación con toda seguridad llevaría a Salazar Bondy a no transigir en su decisión.

Al día siguiente, en el mismo diario, otra nota se sumó a la defensa del bien intencionado abogado: "Concurso La Marinera / Dos folklorólogas discrepan del fallo". Estas folklorólogas eran Rosa Elvira Figueroa, entonces Directora de la Escuela Nacional de Música y Danzas Folklóricas del Perú, y la influyente Rosa Mercedes Ayarza de Morales, que ostentaba el título de "Conservadora del folklore criollo" y que contaba con la autoridad que le daba el haber sido la primera en llevar a la partitura la marinera de Abelardo Gamarra titulada La concheperla. Los amigos del "mecenas", uno a uno, salían en su defensa escandalizados ante la osadía del crítico de arte. "En nuestros anales artisticos desde Pancho Fierro hasta Ángel Chávez, artista premiado por la Municipalidad de Lima, no conocemos otra interpretación de la Marinera si no está realmente significada por dos bailarines. (...) Toda concepción artística, por 
moderna que sea, no puede llegar a desfigurar las reglas inmutables de los bailes que tienen una larga tradición. Con todo el depurado sentido modernista que se quiera hacer prevalecer, debería en todo caso respetarse estas formas que constituyen la esencia de lo tradicional".

Recién el jueves 28 de agosto el escultor ganador se animó a publicar su opinión en $E l$ Comercio. "Debatido caso de certamen escultórico / "Yo he presentado una alegoria de la marinera y no un retrato de ella" dice Alberto Guzmán". "Quienes han censurado mi escultura a la marinera -simbolizada por la figura de una mujer en actitud de danzante-aduciendo que he debido ceñirme al relato de dicho baile, olvidan que el valor documental no es importante en la expresión escultorica, tanto es asi, que la Victoria de Samotracia no es un campo de batalla con vencedores y vencidos sino la efigie individual de una mujer, y que una escultura al fútbol necesariamente no exige 22 jugadores $y$ un referee. (...) Mi obra la he realizado observando principios alegóricos y no ciñéndome al relato o carácter documental de la marinera". El artista termina su inteligente sustentación manifestando su "agradecimiento al señor Revoredo por su encomiable propósito de propiciar estimulo a la escultura que, con o sin marineras, tanto se precisa en nuestro pais".

Al día siguiente la destacada artista Julia Codesido, quien formara parte de la plana mayor del indigenismo, publica una carta en El Comercio en la que confiesa, en su calidad de miembro del jurado, que votó por la obra de seudónimo "Duende", con el propósito de destacar que no fue unánime la elección del ganador. Nos informa que la maqueta de su predilección planteaba "una agrupación escultórica (que) se componia de tres momentos figurativos del baile, dándole gracia y belleza al conjunto". Es curioso que una de las artistas que había conseguido incorporar con éxito la abstracción a su lenguaje, prefiriese engrosar la lista de los amigos del doctor Revoredo.

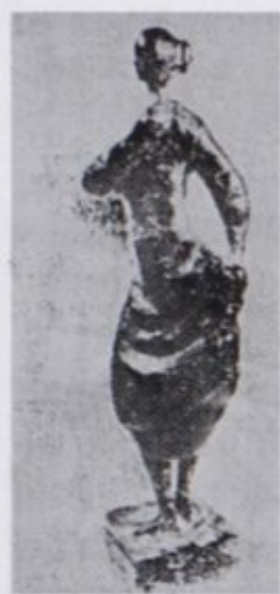

Fig.1

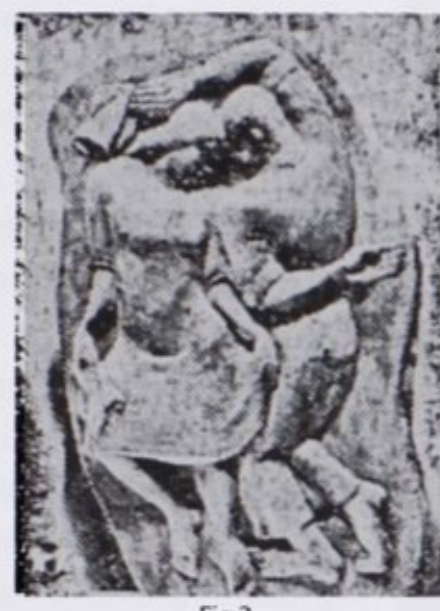

Fig. 2

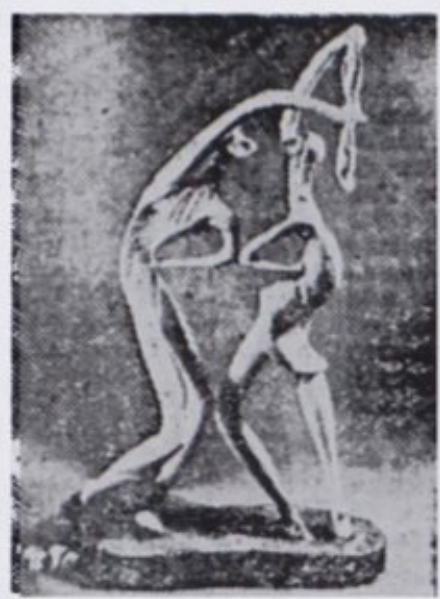

Fig. 3

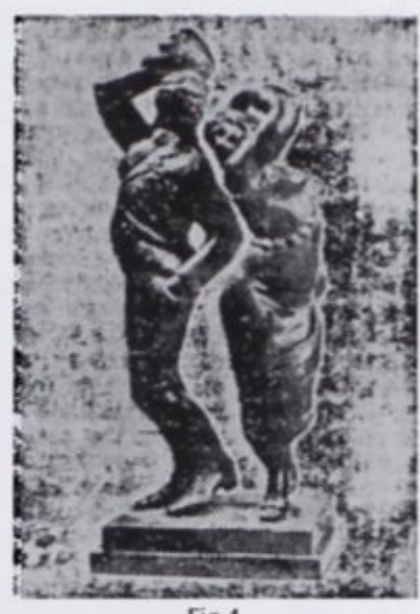

Fig. 4

El domingo 31 de agosto, en su Suplemento dominical, El Comercio publicó una foto de la obra ganadora junto a otras tres de las participantes. No somos tan severos como Sebastián Salazar Bondy al juzgar estas maquetas -que sin duda fueron elegidas para ilustrar esta página por haber competido estrechamente con la ganadora. No hay indicación alguna respecto a la autoría de cada una. La que aparece segunda -mirando de izquierda a derechaes una propuesta de trabajo en "alto relieve", que pareciera ocultar otros dos lados, lo que encajaría con la descripción de "los tres momentos figurativos del baile" que reclamaba Codesido. Al menos coincide con la cuarta maqueta reproducida en tanto su pretensión de representar la marinera con cierta "ortodoxia". La tercera, en cambio, llama nuestra 
atención por ser una propuesta abstracta, entendida como una estilización, bastante jovial, lo que hace evidente que este planteamiento modernista y antitradicional era tolerado en tanto respetaba aquellas características "inmutables". (Esta secuencia fotográfica figura al pie de un extenso artículo de Juan Acha, firmado con su seudónimo, "J. Nahuaca", que se titula (¿casualmente?) "La peruanización de la pintura": “...cuando el pintor adopta iconografias foráneas por simple simpatia racial o cultural, y hace uso ostentoso de ellas, está cometiendo el mismo abuso artístico que en el caso de que use la propia con alarde...").

El martes 02 de septiembre El Comercio publicó una carta del talentoso pintor Ángel Chávez titulada "Sobre concurso La Marinera". En ella, Chávez manifiesta -como si hiciera falta, tal vez por la alusión que hizo Ayarza- su desacuerdo con el artista premiado apoyado en el siguiente argumento: “...en la pintura hay conocidos cuadros referentes a la marinera. Julio Málaga Grenet, José Alcántara La Torre, Francisco Gonzáles Gamarra, la han descrito en la armonía de una pareja. Piqueras Cotoli, Carlos J. Pazos, Ismael Pozo, entre otros, la esculpieron en forma igualmente grupal, y así, también, la han interpretado todos los concursantes al certamen, con prescindencia de la maqueta premiada....". Parecían no darse cuenta que lo pictórico y lo escultórico tienen recursos expresivos particulares y sus propias reglas.

Pero el premio tendría que otorgarse tal como lo informa El Comercio del 09 de septiembre en escueta mención: "Esculturas sobre La Marinera exhibirán en el IAC". Y el siguiente martes, 16 de setiembre: "EI IAC inauguró ayer muestra escultórica y de grabados / Dieron premio La Marinera". En esta ceremonia César Revoredo, y como correspondía en calidad de patrocinador del concurso, pronunció un discurso, algo a lo que -como veremos al final de estas líneas- el abogado era particularmente adicto. Finalmente le pidió a la señora María Pinilla de Mujica que pusiera "la oblación en manos de Alberto Guzmán" para no hacerlo él mismo ${ }^{3}$. En el extracto publicado de dicho discurso no hay ninguna alusión a Salazar Bondy.

Con esta agitada discusión pública en la que los implicados -y quienes se consideraron implicados- se sirvieron de la prensa escrita para exponer sus ideas se cerró este capítulo, que tras su aparente intrascendencia dejó, sin embargo, traslucir una serie de detalles:

- El criollismo/tradicionalismo/limeñismo sólo podía manifestarse para el organizador del concurso en una obra figurativa, a lo sumo en una estilización pero que no debía inventar sino "perpetuar" una tradición. La abstracción, signo de lo moderno -y probablemente de lo efimero para los que vivían añorando el pasado- no estaba a la altura de "la tradición", pues la alteraba. Tradición y antimodernidad. Lo criollo o "el criollismo" no podía tener una versión libre resultado de la abstracción.

- Como toda polémica de indole cultural nunca sobrepasa, en nuestro ámbito, el círculo de los entendidos y diletantes, las vicisitudes de este concurso son bastante

3 En la misma página de El Comercio figura una nota informativa titulada "Entregan pergamino al Dr. C. Revoredo". "Conocidas personalidades vinculadas al ambiente de la música criolla y folklórica, se reunieron ayer en la tarde, en significativa ceremonia, en homenaje al doctor César Revoredo, distinguido folklorista, que desde la institución "Ritmos peruanos", estimula a los que se dedican a la música y el folklore peruano. En dicho acto, fue entregado al doctor Revoredo un pergamino como reconocimiento a su labor artística. El doctor Revoredo agradeció en fina improvisación el homenaje que se le tributaba". Tal parece que desde acto que le sirvió de paliativo o desagravio, Revoredo acudió a entregar el premio. 
reveladoras del estado cultural en el que incluso los intelectuales y artistas se hallaban ante la aparición avasalladora de las tendencias modernas del arte.

- Que aquellos que gozaban de un bienestar material y una supuesta cultura y que estaban en la posición de disfrutar de su existencia en el Perú del siglo XX. periodo desde el cual oteaban el pasado y el futuro con grandes expectativas, seguian concibiendo "las bellas artes", como entidades románticas, estancadas en el tiempo, y no como disciplinas con las que se modifica, desde la cultura, la percepción de la realidad.

En setiembre de 1959 Alberto Guzmán expuso sus obras lo que motivó que "J. Nahuaca" le dedicara su columna en El Comercio del miércoles 09 de dicho mes. "La escultura de Alberto Guzmán" es una critica positiva al conjunto expuesto ilustrada por una fotografia del joven escultor y "su maestro" Joaquín Roca Rey, frente a escultura del primero.

El domingo 13 de setiembre en su columna del suplemento dominical, ya en El Comercio, Salazar Bondy publica "Guzmán Garcia tras el nuevo signo" de la cual extractamos: "...Guzmán ganó hace poco tiempo (...) el concurso de La Marinera. Aquella vez, obligado por el encargo, sintetizó el grácil movimiento de la figura femenina en el baile, sin importarle la justeza folklórica. En la exhibición de ahora se advierte hasta qué punto lo que interesa a este artista es lo escultórico, que no puede ni debe ser documental".

Para atemperar los elogios, Edgardo Pérez Luna -crítico que guardó sospechoso silencio durante la polémica en cuestiónpublicó en su columna en el mismo diario, el lunes 14 de setiembre: "Exposición de Alberto Guzmán en el $I A C$ ". Crítica positiva pero reservada: “...No obstante la falta del sello personal, la exposición tiene un saldo a favor del artista...".

\section{¿EPÍLOGO?}

Como lo suponemos nunca se erigió el Monumento a La Marinera, que en el peor de los casos habría servido para incluir un auténtico proyecto escultórico en el espacio público que podría haber servido de parangón. Pero César Revoredo se embarcaría en un nuevo proyecto que lo catapultaría, sin duda, como el "mecenas" de la anacronía de las artes plásticas: Dieciséis meses después de otorgado el Premio, exactamente el 18 de enero de

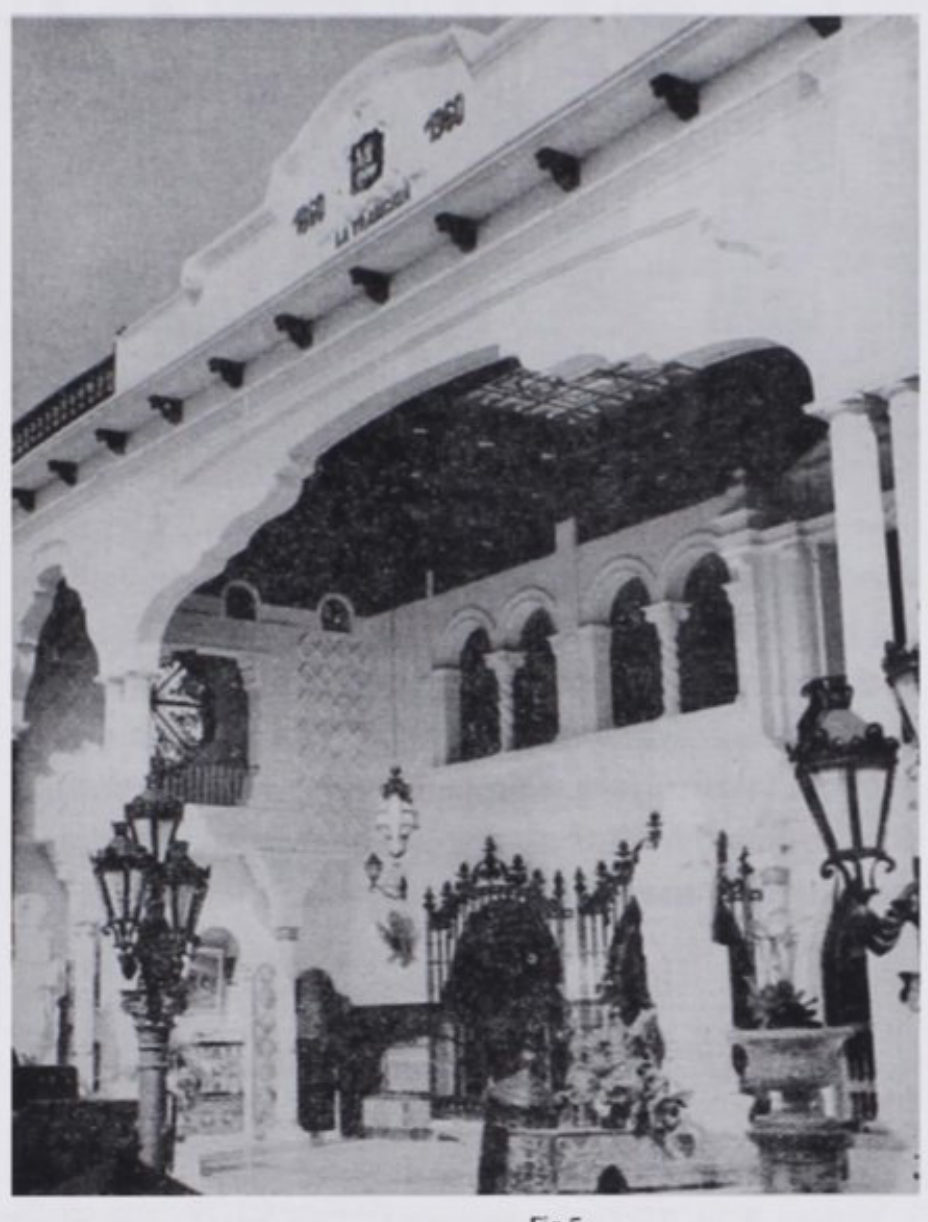

Fig. 5 
1960, Revoredo inauguraría un edificio cuyas características arrojan luz sobre el concepto de cultura que él y los que integraban su círculo cultivaban, y específicamente sobre lo que esperaban del arte: la Casa de la Tradición. Construcción creada en la cuadra 30 de la avenida Salaverry y en la que, equiparando a Walt Disney, contenía dentro de su planta, desde la fachada al claustro interior, en escala risible, elementos de la arquitectura virreinal y republicana limeñas. Para César Revoredo y los ilustres limeños que, como él, se regocijaban de vivir en Lima, gracias al bienestar antes mencionado, cultivar la memoria de una supuesta "tradición" y apostar por ella era algo que proyectaría al país por el camino del progreso. Por eso la "Tradición" no podía adoptar formas abstractas.

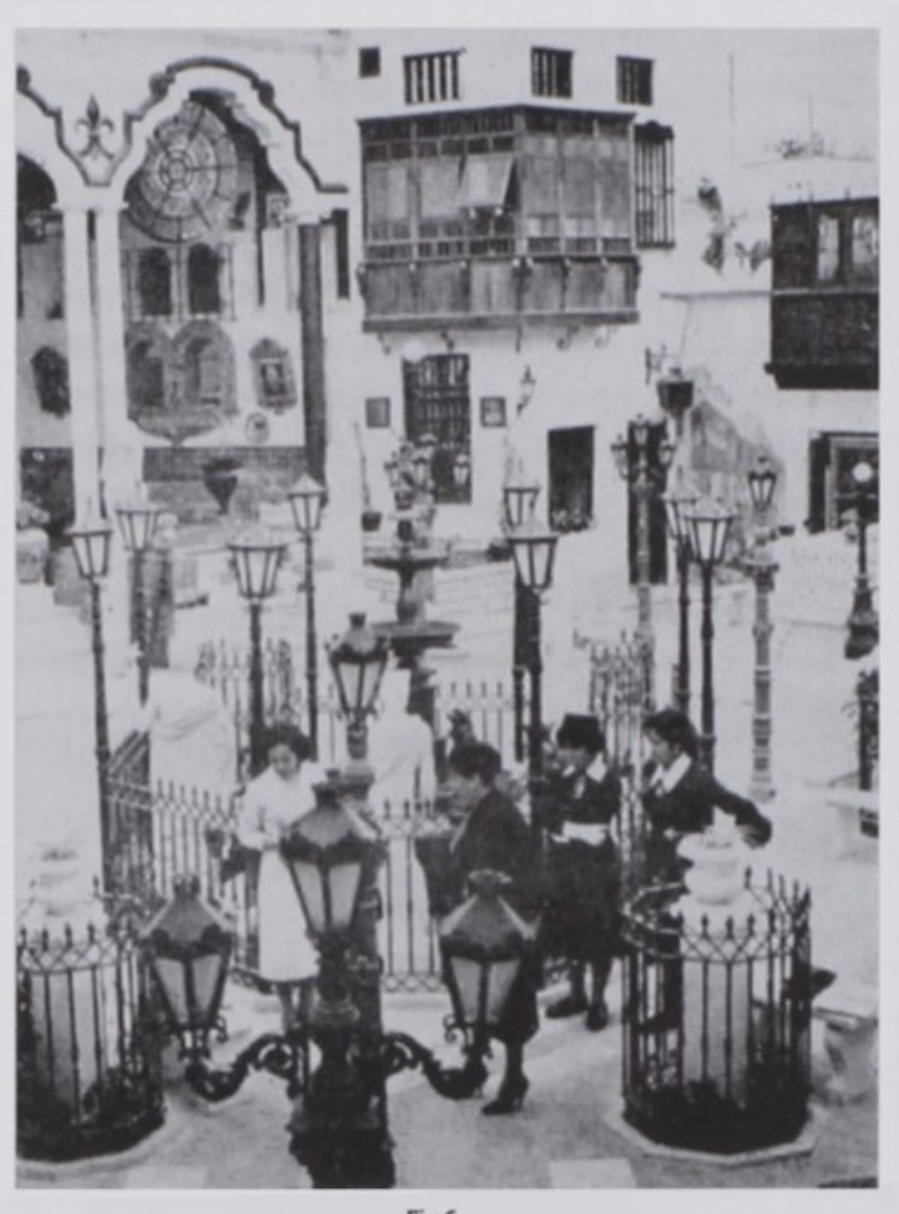

El periodista Ricardo Walter Stubbs, asiduo concurrente a los "actos solemnes" en dicha casa escribión: "La obra total ha sido en buena cuenta un producto de la imaginación del doctor Revoredo, combinando en armonioso conjunto, los trazos que dejaron en torno a la Plaza Mayor principalmente, arquitectos y constructores de siglos pasados, lo que ha sido replicado con habilidad por alarifes $y$ artesanos de hoy. Merece particular mención, los murales que ha dejado allí el notable pintor Vásquez (...). Raúl Pró ha dado bastante de su inspiración para el decorado y algunos bronces han sido ejecutados por el artista Valdettaro". En efecto, a Valdettaro, miembro del jurado, pertenecen dos pequeñas "tapadas" en bronce, sobre el capitel plano de una columna. Rosa Mercedes Ayarza sería madrina de este recinto.

Esta peculiar "creación" incluía la efigie de Ricardo Palma en su fachada, y a la vez farolas, rejas tipo republicano, retratos al óleo de Garcilaso de la Vega, del mismo Palma y de Santa Rosa de Lima, así como armas antiguas. En el patio había mandado a construir una réplica enana de la Plaza de Armas de Lima en la que aparecía la fachada del desaparecido Palacio Arzobispal y la antigua pileta con el también desaparecido Ángel de la Fama, algún rincón de la Alhambra de Granada y la Catedral tenía además en su interior una réplica del altar mayor de la verídica. Todo era una escenografia que pretendía recrear inútilmente una plaza de armas histórica.

“(...) la Plaza de Armas en miniatura obra del doctor Revoredo, resucita la de cien años atrás y es un exitoso esfuerzo que merece no sólo el aplauso, sino el premio con que le hará justicia la ciudad de Lima"s.

REVOREDO, César. Casa de la Tradición. Anales 1960 - 1962. Lima, 1968. P. 22. (Texto firmado en 1967).

" Ibídem. P. 34. (Discurso inaugural de Luis Alayza y Paz Soldán, "padrino"). 
Lo curioso es el estado de "dadaísmo involuntario" que este espacio generó. Entre ellos el más alucinado puede ser aquel "desagravio a Beethoven"6 o el "Homenaje a la Constitución de 1860", año en que el organizador persistía en retrotaer y que lo delataba como un "mecenas" que miraba hacia el pasado.

Miembro de una generación de lectores equivocos de Ricardo Palma, empeñados en materializar aquello que fue mito, convocó al concurso de La Marinera con el propósito de vincular el arte escultórico y la tradición, que fue en verdad, lo que él concebia como "escultórico" y "tradición". La mortificación que el saldo de dicho concurso patrocinado por él fue contrarrestada sin duda con la realización de este proyecto demencial en que la escena cultural alcanzó niveles paródicos. La memoria de cada una de sus actividades y particularmente la anticuada y disforzada prosa empleada son hilarantes. Por ejemplo: "(...) el público (...) ha podido conceptuar la calidad espiritual y peruanista que han inspirado en toda ocasión cada una de las numerosas actuaciones realizadas, como expresión del sentido patriótico que informó la creación y erección de esta Casa para consagrarla al anhelo de exaltar el alma tradicional de Lima y en general del Perú todo. (...) despertar el culto a las glorias $y$ enseñanzas del Pasado, avivando la emoción ciudadana, robusteciendo el amor a los próceres de nuestra historia, ensanchando el horizonte de la visión legendaria de este gran pais nuestro, que fue la Roma de América, en la etapa imperial del Incanato, el aula de la cultura y el señorio en los siglos del virreinato y es ahora, en su momento republicano, centro y atracción de estudiosos y empresarios, por sus ingentes riquezas naturales, por la belleza de sus paisajes idilicos, por la indómita arrogancia de sus montañas, por la inmensidad de sus tesoros espirituales, y por la infinita emoción de su acervo tradicionalista..."7.

\section{COLOFÓN}

Escrito hacia 1962 y publicado en 1964, Lima la horrible, el libro emblemático de la producción intelectual de Sebastián Salazar Bondy parece haberse inspirado para combatir los rescoldos de lo virreinal que eran propugnados por personas como Revoredo y su Casa de la Tradición. En el libro aparece una alusión crítica directa a este edificio, mención con la que finalizamos este trabajo: "En un barrio residencial y tras los artificios de una mansión neo-colonial descabalada, se esconde una réplica de la Plaza de Armas tradicional, de sus edificios religiosos y civicos, de su fuente, sus faroles, sus bancas y sus árboles, todo dentro de una escala pueril y como taimada exhibición de fachadas, portales $y$ balcones. Es ese demencial juguete una especie de postal corpórea, al parecer de unos, de maqueta o decoración teatral, de acuerdo a otros, en donde se violenta tanto la realidad, mediante la fábrica hechiza y la enana desproporción, que envuelve a sus habitantes y huéspedes en un clima de pesadilla. (...) ¿Con qué fin el propietario levantó tan peregrina réplica, a la que hizo nombrar "Casa de la Tradición"? La denominación lo dice todo: intentaba aquel ingenuo rescatar del fondo irreversible del tiempo la colonia, cuyo corazón

6 "Un vesánico atentado destruyó hace pocos días parte de las reliquias que se guardan en la Casa Museo de Bonn, ciudad apacible recostada a las orillas del Rhin (...) Recogiendo la emoción que en nuestro medio social y artistico despertó este acto privado de razón, es que se realiza este festival. Lleva la noble intención de una reparación simbólica y para darle de verdadero homenaje, nos honra la representación del Embajada de Alemania en el Perú....". (Discurso de Revoredo el 11 de junio de ¿1961?).

Ibídem. P. 9 (Texto firmado en 1963). 
fuera, en cierto modo, aquel espacio oficial y público. (...) En algunos tradicionalistas, debido a una incontrolada neoplasia de la nostalgia, actúa la voluntad de situar su sueño retroactivo para poseerlo o para ser poseído por él. En tal extremo, el amor linda con la paranoia. En la arquitectura ha regido la misma quimera de la dicha perdida de otros órdenes, y se ha pretendido retrotraer el pasado al presente para anular de éste lo que posee como apuesta de la esperanza, lo que constituye como puerto de partida hacia nuevos horizontes" ${ }^{\text {. }}$

${ }^{8}$ SALAZAR BONDY, Sebastián. Lima la horrible. Editorial ERA, México, 1964, pp. 88 - 90 